\title{
The role of prosthetic repair in the treatment of an incarcerated recurrent inguinal hernia with acute appendicitis (inflamed Amyand's hernia)
}

\author{
M. A. Küper · A. Kischniak · A. Königsrainer • \\ F. A. Granderath
}

Received: 18 January 2009 / Accepted: 22 January 2009 / Published online: 21 February 2009

(C) Springer-Verlag 2009

To the Editor,

We thank Dr. Chatzimavroudis and colleagues for their reasonable comment on our case report regarding the surgical treatment of Amyand's hernia [1] and congratulate them for the successful treatment of a recurrent Amyand's hernia with simultaneous appendectomy and polypropylene plug repair.

Initially, we agree with the authors regarding the role of prosthetic mesh placement for strangulated groin hernia repair. Several studies could show that an incarcerated groin hernia is not an absolute contraindication for the implantation of non-absorbable meshes, as the complications rates (and especially the infection rates) were similar to those after repair without the use of prosthetic material $[2,3]$.

One argument for mesh implantation, as estimated by the authors, is the increased recurrence rate after herniorrhaphy due to the difficulty of suture placement in inflamed and edematous tissue. However, recurrence rates did not differ in the cited study [2]. In another study, differences were found in the recurrence rates but not in the infection rates. However, patients with inflamed hernia or preoperative peritonitis were excluded from randomization (both of them are present in inflamed Amyand's hernia) [3].

M. A. Küper $(\varangle) \cdot$ A. Königsrainer

Department of General, Visceral, and Transplant Surgery,

University Hospital Tübingen, University of Tübingen,

Hoppe-Seyler-Straße 3, 72076 Tübingen, Germany

e-mail: markus.kueper@med.uni-tuebingen.de

A. Kischniak - F. A. Granderath

Department of General, Visceral and Minimally Invasive Surgery,

Hospital Neuwerk, Mönchengladbach, Germany
Apart from that, there are many risk factors for the development of surgical site infection (SSI), including preexisting infection, older age, abdominal surgery, or contaminated operation [4]. Most of them are present in an Amyand's hernia, as it is an entity which affects mainly older patients with a median peak age of 69 years [5].

In our patient, we chose not to perform a mesh repair based on the intraoperative findings (perforated appendicitis with abscess, not only an inflamed appendix) and the characteristics of the patient (age and comorbidities). However, an evidence-based recommendation for the treatment of incarcerated Amyand's hernia cannot be given, as it is an extremely rare clinical condition.

\section{References}

1. Kueper MA, Kirschniak A, Ladurner R, Granderath FA, Konigsrainer A (2007) Incarcerated recurrent inguinal hernia with covered and perforated appendicitis and periappendicular abscess: case report and review of the literature. Hernia 11:189-191

2. Papaziogas B, Lazaridis Ch, Makris J, Koutelidakis J, Patsas A, Grigoriou M, Chatzimavroudis G, Psaralexis K, Atmatzidis K (2005) Tension-free repair versus modified Bassini technique (Andrews technique) for strangulated inguinal hernia: a comparative study. Hernia 9:156-159

3. Elsebae MM, Nasr M, Said M (2008) Tension-free repair versus Bassini technique for strangulated inguinal hernia: a controlled randomized study. Int J Surg 6:302-305

4. Cheadle WG (2006) Risk factors for surgical site infection. Surg Infect (Larchmt) 7(Suppl 1):S7-S11

5. Meinke AK (2007) Review article: appendicitis in groin hernias. J Gastrointest Surg 11:1368-1372 